\title{
COMPORTAMENTO DO CAFEEIRO CONILON JEQUITIBÁ EM FUNÇÃO DO DÉFICIT HÍDRICO INDUZIDO
}

\author{
Wilian Rodrigues Ribeiro' \\ Vinicius Agnolette Capelini² \\ Daniel Soares Ferreira ${ }^{3}$ \\ André Alves Pinheiro ${ }^{4}$ \\ Rogério Rangel Rodrigues ${ }^{5}$ \\ Edvaldo Fialho dos Reis ${ }^{6}$
}

Resumo: A deficiência hídrica pode afetar negativamente o desempenho das culturas no campo. Porém a forma e a intensidade em que cada planta é afetada dependerão diretamente de fatores intrínsecos relacionados à sua espécie ou variedade. Devido a isto o presente estudo buscou avaliar e o comportamento de quatro clones que compõem a variedade jequitibá Incaper ES 8122, perante o déficit hídrico induzido, sob a variável diâmetro de caule e assim quantificar seus efeitos. $O$ experimento foi conduzido em casa de vegetação da Universidade Federal do Espírito Santo, em um esquema fatorial $4 x$ 2, sendo clones em 4 níveis e déficit hídrico em 2 níveis, em um delineamento inteiramente casualizado com 4 repetições. Os 2 níveis de déficit hídrico foram (TO - não sofrerá déficit hídrico; Td - déficit hídrico induzido até as plantas atingirem $10 \%$ da transpiração relativa do tratamento T0). Após as plantas do tratamento Td atingirem o limite pré-estabelecido, passaram a ser irrigadas diariamente e durante 30 dias foi avaliado sua recuperação. Concluiu-se que os clones possuem necessidades hídricas distintas e também respondem de forma específica ao déficit hídrico.

Palavras-chave: Cafeicultura; Conilon Jequitibá; Déficit Hídrico; Recuperação pós-déficit hídrico.

\footnotetext{
${ }^{1}$ Agronomia/Universidade Federal do Espírito Santo/Alegre-ES, Brasil. Email: wilianrodrigues@msn.com.

2 Agronomia/Universidade Federal do Espírito Santo/Alegre-ES, Brasil. E-mail: vinicius91ac@hotmail.com.

3 Agronomia/Universidade Federal do Espírito Santo/Alegre-ES, Brasil. E-mail: danielufes@live.com.

${ }^{4}$ Agronomia/Universidade Federal do Espírito Santo/Alegre-ES, Brasil. E-mail: aalvespinheiro7@gmail.com.

${ }^{5}$ Agronomia/Universidade Federal de Lavras/Lavras-MG, Brasil. E-mail: rogeriorr7@hotmail.com.

${ }^{6}$ Agronomia/Universidade Federal do Espírito Santo/Alegre-ES, Brasil. E-mail: edreis@cca.ufes.br.
} 